\title{
Splenic melanosis during normal murine C57BL/6 hair cycle and after chemotherapy*
}

\author{
Dominika Michalczyk-Wetula, Aleksander Salwiński", Małgorzata Popik ${ }^{\# \#, ~ M o n i k a ~ J a k u b o w s k a ~}$ \\ and Przemysław M. Płonka
}

Department of Biophysics, Faculty of Biochemistry, Biophysics and Biotechnology, Jagiellonian University, Kraków, Poland

\begin{abstract}
Cancer chemotherapy is associated with serious side effects, including temporary hair loss and impairment of pigmentation. We suspect that ectopic melanin deposition occurring due to chemotherapy may add to these effects worsening the already unpleasant symptoms. We associated the ectopic occurrence of follicular melanin after chemotherapy with splenic melanosis - an interesting example of extradermal melanin localization - and we expected an increase in splenic melanin deposition after chemotherapy. Using the C57BL/6 murine model of synchronized hair cycle induced by depilation, we visualized splenic melanin by means of several histological and histochemical protocols of staining: hematoxylin and eosin, May-Grünwald-Giemsa and Fontana-Masson. Unexpectedly, the splenic deposition of melanin decreased due to application of cyclophosphamide (i.p. $120 \mathrm{mg} /$ kg body weight on day 9 post depilation). The drop was abrupt and lasted for at least 5 days (day 13-18 post depilation), as compared with normal hair cycle. Moreover, in mice with normal, depilation-induced hair cycle we observed a similar drop shortly before entering catagen (day 15 post depilation), followed by a slow and partial increase in splenic melanization up to day 27 post depilation in both groups. We conclude that cyclophosphamide negatively affects splenic melanization and/or extradermal transfer of ectopic melanin from the dystrophic hair follicles, but the most powerful down-regulator of splenic melanosis is normal and dystrophic catagen - the phase of hair follicle involution and re-modelling.
\end{abstract}

Key words: cyclophosphamide, Fontana-Masson, hematoxylin and eosin, May-Grünwald-Giemsa, melanin, spleen

Received: 15 May, 2013; accepted: 26 June, 2013; available on-line: 05 July, 2013

\section{INTRODUCTION}

One of the most acute side effects of cancer chemotherapy is hair loss and impairment of hair pigmentation. This phenomenon adds to the overall depressive condition of patients making them feel devastated and is sometimes a reason for giving up chemotherapy (McGarvey et al., 2001). Understanding the underlying mechanisms is, consequently, an important factor of the success in cancer therapy. One of the related problems is the fate of epidermal and follicular melanin which is initially deposited ectopically in response to chemotherapy (Braun-Falco, 1961). This melanin is toxic in itself (Slominski et al., 1996; Swartz et al., 2005; Wood et al., 2009) and affects the general condition of the organism.
Moreover, the pigmented tumors (melanotic melanoma) may also reveal symptoms of deregulated melanogenesis, which may influence the process of therapy (Plonka et al., 2003; Lazova et al., 2010). This makes the topic of extradermal melanin transfer important also from the oncological point of view (Michalczyk et al., 2009).

Melanin, an amorphous polymer responsible for skin and hair pigmentation, may be also found in other organs. In higher vertebrates, including humans (Wasserman, 1967), melanin has been reported, besides skin, in visceral organs, and its presence and origin in such extradermal locations is enigmatic. Pigmentation of murine spleens was noted for the first time by Weissman (1967). Early studies delivered numerous hypotheses concerning the identity of the pigment. In (1978) Crichton et al. identified the pigment as lipofuscin. In (1989) Veninga et al. postulated deposition of hemosiderin as the cause of spleen pigmentation. Work of Sundberg et al. (1991) and van der Heijden et al. (1995) finally confirmed the presence of melanin. Simultaneously, they excluded lipofuscin - the pigment characteristic for ageing, since the phenomenon was observed in young animals. The presence of melanin was directly proved by Plonka et al. (2005) by means of electron paramagnetic resonance (EPR, also called electron spin resonance, ESR). In (2009) Michalczyk et al. indicated that partial melanization of spleens is observed in young C57BL/6 mice (younger than 10 weeks) with synchronized hair cycle. Meanwhile, over one-year-old mice revealed no splenic melanosis, instead, "melanin debris" could be observed in some of these old mice.

Excessive melanin deposition (melanosis) of inner organs is a long-studied phenomenon (Wasserman, 1967). It has recently turned out that melanophores play an important part in amphibian metamorphosis, which includes total re-building of the tissues, including skin. An interesting manifestation of this process is deposition of mel-

e-mail: przemyslaw.plonka@uj.edu.pl

* Presented at 40th Jubilee Winter School of the Faculty of Biochemistry, Biophysics and Biotechnology of the Jagiellonian University "Contemporary insights into cancer. Risk, perspectives, expectations", February 16-21, 2013, Zakopane, Poland.

\#Present address: Institute of Organic and Analytical Chemistry (ICOA), UMR 7311, University of Orléans, BP 675945067 Orléans cedex 2, France.

\#\#Present address: IBSS BIOMED S.A., Sosnowa 8, 30-224 Kraków, Poland.

Abbreviations: C57BL/6, Cross 57th-generation female $\times 52$ ndgenertion male BLack, 6th sub-strain (inbred mouse strain); CYP, cyclophosphamide; DPPH, 1,1,-diphenyl-2-picrylhydrazyl; EPR, electron paramagnetic resonance; ESR, electron spin resonance; FM, Fontana-Masson; HE, hematoxylin and eosin; MGG, May-GrünwaldGiemsa. 
anin in the liver and other visceral organs of the animals (Divya et al., 2010). Understanding the origin and mechanism of splenic melanization in mice is, therefore, important from the point of view of general biology, evolution of the skin, and experimental dermatology (Rakers et al., 2010). The most important, hypothetical extrasplenic source of the murine spleen melanin are the hair follicle melanocytes.

The mammalian hair follicle is a mini organ, which undergoes continuous remodelling through the whole animal life in the process called hair cycle (Chase, 1954; Müller-Röver et al., 2001). In many animals, including mice, it is synchronized over big areas of skin (Dry, 1926). The hair grows and gains melanin only in anagen - the stage of hair growth. In the subsequent stage catagen (well synchronized in young C57BL/6 mice, and followed by telogen, the "resting" stage), follicular melanocytes undergo massive apoptosis, and the melanincontaining apoptotic bodies are phagocytosed initially by the Langerhans cells (Tobin, 1998) and then transferred further, probably as far as to the spleen. In the meantime melanin undergoes partial degradation (Borovansky \& Elleder, 2003; Plonka et al., 2005). Therefore, splenic melanization must be correlated with the progress of the hair cycle.

Impairment of the hair cycle and of the related melanin production is often associated with ectopic deposition of the pigment in the hair follicle outside the hair shaft. Such pathological melanization is a side-effect of cancer chemotherapy with cyclophosphamide (CYP) in humans (Braun-Falco, 1961), and in model mice (Kostanecki et al., 1967). This is a rationale to suppose that in such a case a particular increase in splenic melanin deposition can be expected. On the other hand, in normal mice we found less splenic melanin in early telogen than in late telogen (Plonka et al., 2005) while one of the ways through which hair follicles can recover from CYP-related dystrophy is to enter dystrophic catagen followed by dystrophic telogen (Paus et al., 1994a). It creates the necessity to assess splenic melanosis over the whole hair cycle, in its every stage, with and without CYP administration. The presence of melanocytes in murine skin is limited almost exclusively to hair follicles (Chase, 1954; Slominski et al., 2005). Since these laboratory rodents exhibit the wave-like type of hair growth (Dry, 1926; Chase, 1954; Chase \& Eaton, 1959), synchronization of every stage of the hair cycle is possible, which is even more prominent in the case of the depilation-induced cycle (Paus et al., 1990). Therefore, this model is of particular suitability to study correlation between splenic melanosis and hair cycling.

For microscopic examination of splenic melanosis we chose three methods of histological staining often applied in experimental dermatology: hematoxylin and eosin (HE; Paus et al., 1999b; Müller-Röver et al., 2001; Shirai et al., 2001; Hendrix et al., 2005), May-Grünwald-Giemsa (MGG; Paus et al., 1994b; Müller-Röver et al., 2001; Lu et al., 2009), as well as Fontana-Masson (FM; Slominski \& Paus, 1993; Slominski et al., 1994; 2004; 2005).

One of the most popular and widely applied is hematoxylin and eosin staining (Mayer, 1891; 1904). It employs two dyes specific for different cell compartments. Hematoxylin, a blue dye, possesses affinity to basophilic (acidic) structures within the cell (mainly chromatin, therefore the nucleus is visualized very efficiently). To obtain a sharp contrast with the blue hematoxylin signal, the staining with purple eosin $\mathrm{Y}$ is used. This dye shows affinity to acidophilic structures (usually positively charged, because eosin is an acid). In practice, eosin stains the entire cytoplasm and cell membrane of various types of cells (Romeis, 1991; Avwioro, 2011).

Another staining method whose specificity is based on electrostatic interactions between the dye and the target structures is May-Grünwald-Giemsa stain (MGG). MayGrünwald staining solution is composed of eosin Y and methylene blue. Giemsa solution is applied separately and is composed of azure-type dyes: azure II is a mixture of methylene blue and its derivative in 1:1 proportions, and of eosin. The Properties of azures and methylene blue are similar to those of hematoxylin — these dyes, carrying a positive charge, stain nuclei and basophilic cells (Barcia, 2007).

The third staining procedure is based on the reduction of diamminesilver(I) nitrate to metallic silver(0) under the influence of reductive agents present in the cell. This method, described by Fontana (1912) and Masson (1914), was applied by Fontana for visualization of a spirochete (Treponema pallidum), and in its basic version it is known as Fontana-Masson (FM) staining. Masson applied 'silver solution' for visualization of neuronal structures (Moore et al., 2001). Cells which reduce diamminesilver(I) nitrate to metallic silver $(0)$ are referred to as argentaffins. A positive result of such 'silver stain' is mostly correlated with the presence of serotonin (Barter \& Pearse, 1955) and other biogenic amines such as dopamine or ephedrine (Lundqvist et al., 1990). Melanins are composed mainly of derivatives of dihydroxyindole monomers that can be oxidized by diamminesilver(I) nitrate and thus melanins can be marked with metallic silver(0) (reaction 1).

$$
\left\{\begin{array}{l}
\mathbf{n}\left\{\left[\mathrm{Ag}^{(\mathrm{I})}\left(\mathrm{NH}_{3}\right)_{2}\right]^{+}(\mathrm{aq})+e^{-} \rightarrow \mathrm{Ag}^{(0)} \downarrow+2 \mathrm{NH}_{3}(\mathrm{aq})\right\} \\
\text { melanin(reduced) } \rightarrow \text { melanin(oxidized) }+\mathrm{n} e^{-}
\end{array}\right.
$$

Reaction 1. Schematic illustration of the principle of silver(I)-dependent oxidation of melanin.

EPR spectroscopy is widely used to investigate melanin-containing tissues. Paramagnetic properties of this pigment were pointed out for the first time in 1954 (Commoner et al., 1954). Since then EPR has been applied to quantitative (Pilas \& Sarna, 1985; Slominski et al., 1994), and qualitative (Sealy et al., 1982) assays of melanin and of its microenvironment in the tissue (Felix et al., 1978; Plonka et al., 2005). It is, however, not able to localize melanin spatially in the spleen tissue. Instead one is bound to use standard histological methods.

In the present paper we compared $\mathrm{HE}$ and MGG staining and the FM method, which is melanin-specific in terms of quality and potential to visualize melanin and the contours of individual cells, in murine C57BL/ 6 spleens. The presence of melanin was verified independently by means of EPR spectroscopy. We checked the presence of splenic melanosis on subsequent days after induction of the hair cycle by depilation. We also examined whether chemotherapy with CYP increases or decreases splenic pigmentation, and discussed what implications it may have for cancer treatment.

\section{MATERIALS AND METHODS}

Instruments. Paraffin slices were prepared using a manual Finesse 325 microtome (Thermo Shandon, Runcorn, UK), images of stained tissues were taken by a reversed Eclipse Ti microscope (Nikon Corporation, Tokyo, Japan) equipped with the Nis elements F 3.0 imaging software (Nikon Corporation, Tokyo, Japan), and an analog camera (PENTAX ME, Asahi Opt. Co., Tokyo, Japan) equipped with 1:4.5/8-20 $\mathrm{mm}$ Soligor MC lenses (Sun 
Optical Co., Ltd., Ichikawa, Japan) adjusted for macrophotography. EPR spectra were recorded by an E-3 spectrometer (Varian, Sunnyvale, LA, USA) in a Wilmad finger quartz Dewar WG-816-B-Q (Rototec-Spintec $\mathrm{GmbH}$, Griesheim, Germany). Animals were shaved with an animal shaver (Braun AG, Kronberg, Germany).

Reagents. Giemsa, May-Grünwald, ethyl eosin and 1,1-diphenyl-2-picrylhydrazyl (DPPH) were purchased from Sigma-Aldrich Corporation, (St. Louis, MO, USA), Mayer hematoxylin from Aqua-Med (Lódź, Poland), silver nitrate, methyl red, sodium thiosulfate, methyl salicylate, sodium thiosulfate, ethanol, formaldehyde and xylene from POCh (Gliwice, Poland), ammonia from Eurochem Service Poland Sp. z o.o. (Warszawa, Poland), Sedazin ${ }^{\circledR}$ from Biowet Puławy Sp. z o.o. (Puławy, Poland), ketamine (Ketanest $50^{\circledR}$ ) from Parke-Davis $\mathrm{GmbH}$ (Berlin, Germany), cyclophosphamide (CYP; Endoxan ${ }^{\circledR}$ ) from ASTA Medica AG (Frankfurt, Germany), saline from Polpharma SA (Stargard Gdański, Poland), paraffin from Thermo Shandon (Runcorn, UK), beeswax from Aldrich Chemical Co. (USA), and gum rosin from Sigma Chemical Co. (USA). For histology, Polysine ${ }^{\circledR}$ slides and Consult Mount (mounting medium) were obtained from Thermo Shandon, (Pittsburgh, USA), and cover glasses (Citoglas ${ }^{\circledR}$, China) from ElektroMed (Niepołomice, Poland).

Biological material. The biological material was collected over a long time and during several different experiments, all of which were approved by the $1^{\text {st }}$ Local Committee for Animal Research in Kraków (221/95, 303/97, 15/OP/2004). Female, 6-8-week-old C57BL/6 mice (Animal Breeding Facility, Silesian Medical Academy, Katowice-Ligota, Poland) were selected for depilation based on the pink color of their back skin (all hair follicles in telogen, Paus et al., 1990). Depilation was executed in ketamine anesthesia by application of melted 1:1 mixture of beeswax and gum rosin and peeling out the hair coat after hardening, according to Paus et al., (1990). On day 9 post depilation (p.d.) the CYP-treated animals were administered a single i.p. dose $(120 \mathrm{mg} / \mathrm{kg}$ body weight) in a small volume (ca. $0.1-0.2 \mathrm{ml}$ ) of saline (Paus et al., 1994a; Hendrix et al., 2005), while the control animals were given vehicle. At subsequent time points (see Fig. 1) the animals were shaved if necessary, photographed, and killed by cervical dislocation in deep ketamine anesthesia, whereupon the skin was separated at the level of subcutis, spread on a piece of cardboard, and fixed in buffered $5 \%$ formalin (phosphate buffer, $\mathrm{pH}=7.4$ ). We determined the stage of the hair cycle and dystrophy of the hair follicles based on the tabularized criteria of histomorphometry (Müller-Röver et al., 2001; Hendrix et al., 2005).

The spleens of animals were carefully examined on necropsy for macroscopic evidence of melanosis and fixed in the formalin solution for histology. We estimated the area of melanosis and calculated the percentage of melanotic spleens per a given experimental group of mice. A part of spleens was frozen in liquid nitrogen for EPR measurement.

Preparation of tissue slices for histology. To prepare paraffin blocks, the spleens, after a long fixation in formalin, were rinsed with water $(24 \mathrm{~h})$, dehydrated in the series of aqueous solutions with increasing concentration of ethanol $(50 \%-1 \mathrm{~h}, 70 \%-2 \mathrm{~h}, 80 \%-2 \mathrm{~h}, 96 \%-12 \mathrm{~h}$, $100 \%-40 \mathrm{~min}, 100 \%-1 \mathrm{~h})$ and then in methyl salicylate (4 h), xylene (10 $\mathrm{min}$ ) (all at room temperature) and embedded in paraffin blocks. Shortly before cutting into $5 \mu \mathrm{m}$ slices the paraffin blocks with embedded spleens were additionally cooled in icy water. We found it an important step preventing the spleen tissue from crumbling.

The middle-dorsal pieces of skin were flushed with water $(24 \mathrm{~h})$, dehydrated in a series of ethanol solutions $(50 \%-1.5 \mathrm{~h}, 70 \%-1.5 \mathrm{~h}, 80 \%-1.5 \mathrm{~h}, 96 \%-12 \mathrm{~h}$, $2 \times 100 \%-30 \mathrm{~min})$, immersed in anhydrous ethanol and xylene $(1: 1, \mathrm{v}: \mathrm{v})(2 \times 30 \mathrm{~min})$ and xylene $(30 \mathrm{~min})$ (all at room temperature), embedded in paraffin blocks, and cut in $8 \mu \mathrm{m}$ slices.

Pre-treatment of slides with tissue sections. Paraffin sections of spleen tissues on Polysine ${ }^{\circledR}$ slides were deparaffinized by: a) incubation of the slides in $56^{\circ} \mathrm{C}$ for 20 min to melt paraffin and to attach the tissue to the surface of glass, b) dissolution of the melted paraffin in xylene (5 min) and then immersing the slides in fresh xylene several times, and c) re-hydration of the tissue by immersing the slides in a series of aqueous solutions with decreasing concentration of ethanol $(100,96,80,70,50$, $0 \%$ of ethanol, v/v, respectively).

Hematoxylin and eosin (HE) staining. The deparaffinized slices were incubated in hematoxylin working solution (12 min) at room temperature, flushed with tap water $(15 \mathrm{~min})$, counterstained for $1.5 \mathrm{~min}$ in $0.1 \%$ ethanol solution of eosin acetified with a few drops of acetic acid, dehydrated in the ethanol series $(70 \%, 2 \times 96 \%, 2 \times 100 \%, \mathrm{v} / \mathrm{v}$, respectively), $2 \times$ xylene (all at room temperature), sealed in balsam and covered (Romeis, 1991).

May-Grünwald-Giemsa (MGG) staining. Working solution of Giemsa was prepared by mixing 0.5 $\mathrm{ml}$ of concentrated Giemsa stock solution with $200 \mathrm{ml}$ of distilled water. The MG working solution was prepared by mixing $15 \mathrm{ml}$ of MG stock solution with $160 \mathrm{ml}$ of distilled water. Deparaffinized slides with samples were incubated in $\mathrm{MG}$ working solution for $20 \mathrm{~min}$ at $37^{\circ} \mathrm{C}$ in a Coplin jar covered with aluminium foil to protect against light. The samples were then introduced into Giemsa working solution for $40 \mathrm{~min}$ at $37^{\circ} \mathrm{C}$, immersed quickly in $0.15 \%$ solution of acetic acid to obtain neutral $\mathrm{pH}$, washed in distilled water,
Figure 1. Experimental design.

Empty circles, harvesting of spleens; black circles, harvesting of skin. Below, general scheme of normal hair cycle in C57BL/6 mice, and dystrophic hair cycle after administration of cyclophosphamide (i.p. $120 \mathrm{mg} / \mathrm{kg}$ body weight) on day 9 post depilation (according to Müller-Röver et al., 2001, and Hendrix et al., 2005). 
dehydrated, sealed in balsam and covered with glass coverslip like for HE staining (Zawistowski, 1983).

Fontana-Masson (FM) staining for melanin. Due to the sensitivity of the applied ammoniacal silver nitrate, it was prepared immediately before the staining procedure. Concentrated ammonia was added drop by drop to $20 \mathrm{ml}$ of $10 \%$ solution of silver nitrate until the white precipitate of silver(I) oxide was almost dissolved (hardly noticeable opalescence). The obtained solution was diluted by adding $20 \mathrm{ml}$ of distilled water, then filtered and stored at $4^{\circ} \mathrm{C}$ in a bottle protected from light.

Deparaffinized slides with samples were rinsed in distilled water and incubated in silver solution for $40 \mathrm{~min}$ at $56^{\circ} \mathrm{C}$ in a Coplin jar covered with aluminium foil, while the control slides were incubated similarly in distilled water. After washing in distilled water, the slides were incubated in $5 \%$ sodium thiosulphate (3 $\mathrm{min})$, flushed with tap water ( $3 \mathrm{~min})$, counterstained in $0.5 \%$ aqueous solution of toluylene red (neutral red) for $5 \mathrm{~min}$ to stain nuclei, flushed with tap water again, dehydrated by immersion for a few seconds in the ethanol series (70, 96 and $100 \%, \mathrm{v} / \mathrm{v} ; \times 2 \mathrm{each})$ and then in xylene $(10 \mathrm{~min})$, whereupon the slides were conserved with balm and covered with a glass coverslip (Bancroft \& Stevens, 1982).

EPR measurements. Whole amelanotic and melanotic spleens were analyzed in a Dewar quartz tube in liquid nitrogen $(77 \mathrm{~K}$ ) at X-band (ca. 9.2 GHz), $4 \mathrm{~mW}$ microwave power and $5 \mathrm{Gs}$ modulation amplitude. Amplification of the signal was set at $8 \times 10^{5}$ (melanotic spleens) or $1.25 \times 10^{6}$ (amelanotic spleens). Each spectrum was averaged from 3 scans at $200 \mathrm{~s}$ scan time and $0.3 \mathrm{~s}$ time constant.

Statistical evaluation of the data. We examined 1-5 experimental groups, each of 2-8 animals, per time point (5-22 animals per time point). We expressed the average melanotic area of a spleen ( $\%$ of the total area) as the mean of the pooled data for a time point \pm S.E. We also calculated the total percentage of spleens revealing melanosis per time point (i.e. pooled groups examined at a given time point). Altogether we examined 161spleens (92 control and 69 CYP-treated). The two-tailed independent Student's $t$-test was used to evaluate the statistical significance of the differences between the means, and the Snedecor F test to assess the significance of the differences in variances. The differences were accepted as significant for $\mathrm{p}<0.05$.

\section{RESULTS AND DISCUSSION}

\section{Visualisation of splenic melanin}

Splenic melanosis manifests itself macroscopically (Fig. 2A-D) and has been described in C57BL mice as "black spots" (Weissman, 1967). It is a "yes-or-no" phenomenon, and for yet unknown reasons in all investigated groups there are animals with either melanotic, or non-melanotic spleens. As a result, in a given animal the existence of splenic melanosis cannot be determined without laparotomy (Weissman, 1967; van der Heijden et

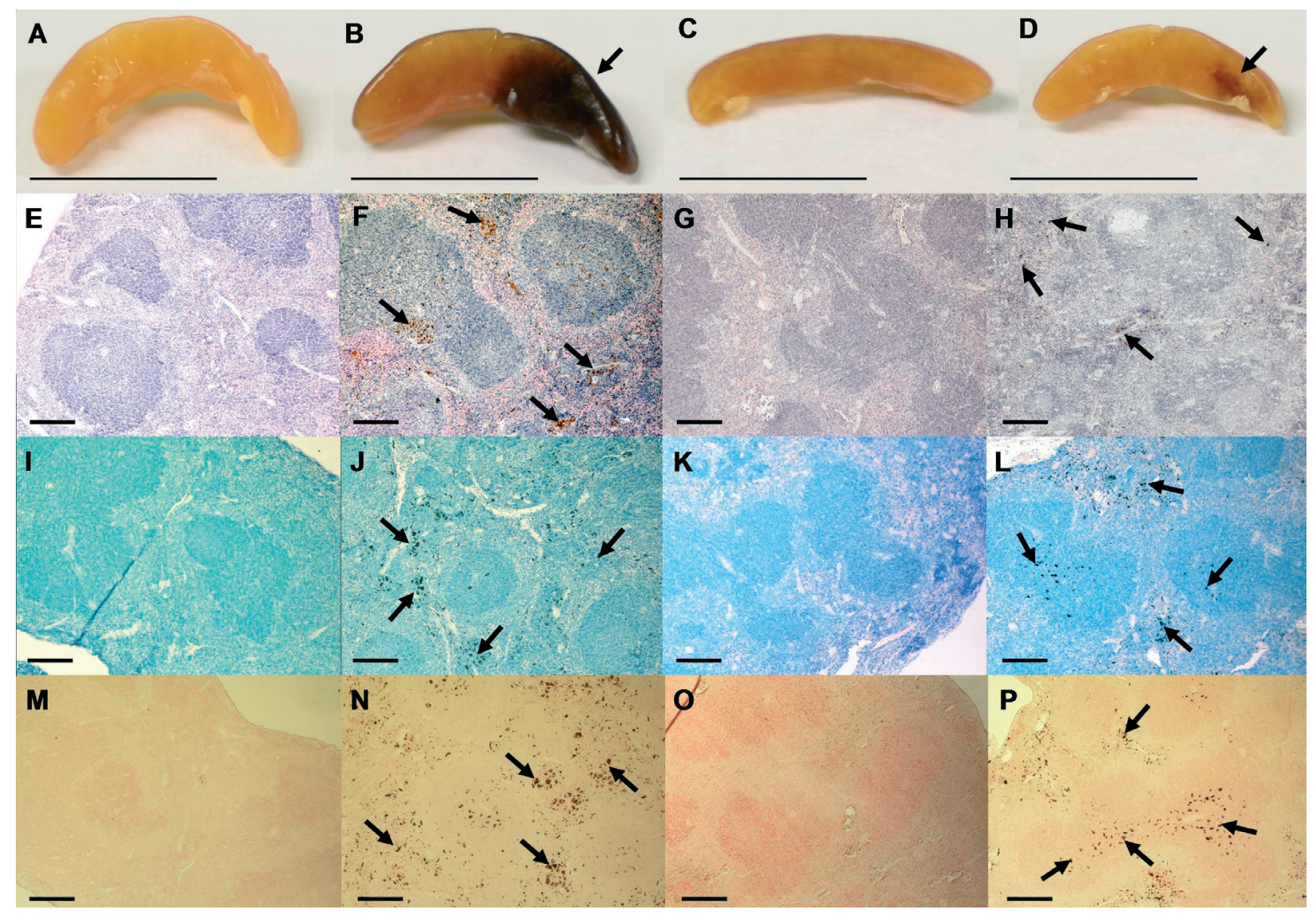

Figure 2. Macroscopic (A-D) and microscopic (E-P) manifestation of splenic melanosis in C57BL/6 mice.

Black spots in normal (B); and cyclophosphamide-treated (D; i.p. $120 \mathrm{mg} / \mathrm{kg}$ body weight, on day 9 p.d.) spleens and amelanotic spleens (A, C, respectively). E-P, corresponding histological examinations of spleens from pictures A-D (respectively). E-H, hematoxylin and eosin staining; I-L May-Grünwald-Giemsa staining; M-P, Fontana-Masson histochemistry. Arrows, melanin. Untreated amelanotic spleen (A, E, I, M) - day 15 p.d., the other pictures - day 13 p.d. Scale bars: A-D, 1 cm; E-P, $100 \mu \mathrm{m}$. 


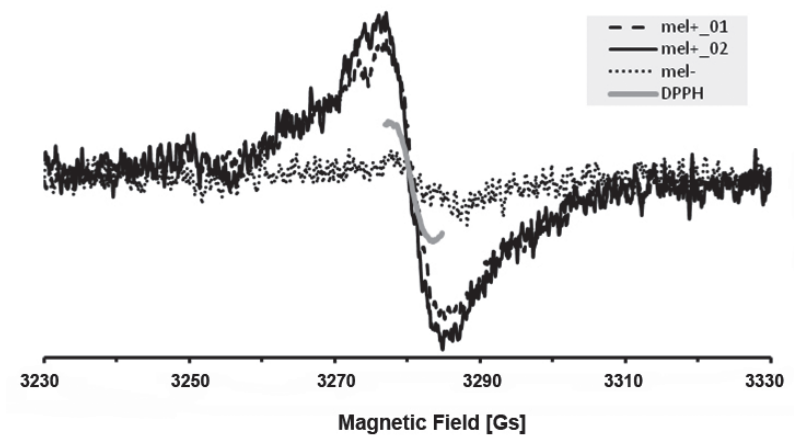

Figure 3. Electron paramagnetic resonance signals of normal C57BL/6 murine spleens.

mel+_01, mel+_02, melanotic spleens (day 15, and day 0 p.d., respectively). mel-, amelanotic spleen (day 0 p.d.). DPPH, the free radical standard. For parameters of EPR assay see "Material and Methods".

al., 1995; Plonka et al., 2005). On the other hand, as the black spot is sharply separated from the amelanotic background, it is easy to assess melanosis macroscopically as the average percentage of the melanotic area of spleens and the percentage of mice revealing melanosis in a given group.

We have shown here that melanin granules can be histologically visualized by means of all the applied methods. As it can be seen in Fig. 2E-P, the depicted melanin granules are dyed in a comparable way - the gamut of colors ranges from yellow-brown to black. On the basis of the properties of the applied chromophore molecules, one may attribute the positive result of staining to basic dyes (methylene blue and its derivatives) due to the negative net charge of melanin. However, a touch of yellow (e.g. Fig. 2F) suggests a contribution of eosine $\mathrm{Y}$, possibly thanks to the $\pi-\pi$ stacking interaction (similar to that present in the aggregates of eumelanin promolecules; Meredith \& Sarna, 2006).

Metallic silver (Fig. 2M-P) has been shown to be an effective marker of melanin granules in Fontana-Masson staining (Slominski et al., 1994; 1996; 2004; 2005). However, to prevent 'false positive' results, the time of incubation in the solution of diamminesilver(I) nitrate should not be exceeded. According to our observations, a significant concentration of melanin may sometimes lead to the excessive intensity of silver deposition, and prolongation of the incubation time may lead to non-specific precipitation of silver(0), possibly due to other mild reducing agents apparently present in cells. Nevertheless, while the time of incubation in "silver solution" should always be carefully considered, sometimes a slight prolongation or even moderate heating of the bath increases the quality of the picture. To sum up, a negative control (incubation without silver nitrate) is always indispensable.

It should be stressed that neither of the two "non-silver" methods (HE or MGG), stains melanin specifically. Their role is to increase the contrast between the background and melanin granules. On the contrary, FM staining is the method which directly, histochemically stains melanin and as such, it may be applied to confirm the reducing potential of the previously visualized granules.

A perfect, independent method to determine directly the presence of melanin in a given sample is EPR spectroscopy (Sarna \& Plonka, 2005). The results of EPR assay of the spleens of young mice with the presence (mel+) and the absence of visible melanization (mel-) are shown in Fig. 3. Additionally, an EPR spectrum of DPPH was recorded as a free radical standard $(g=2.0037 \pm 0.0002$; Wertz \& Bolton, 1984). The shape
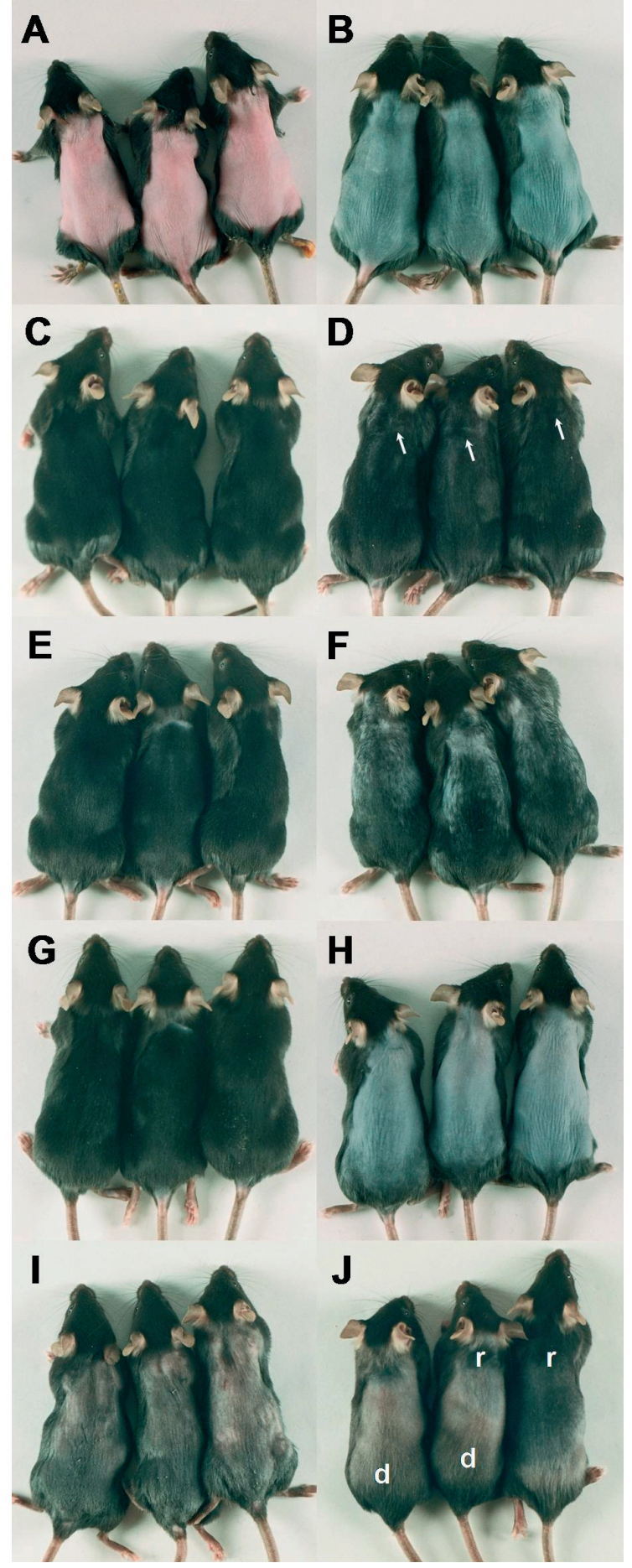

Figure 4. Macroscopic manifestation of hair cycle and cyclophosphamide-induced alopecia in C57BL/6 mice.

(A) female, 7 week-old mice were depilated in telogen (day 0 , note the pink color of the back skin), and (B) injected i.p. CYP (120 mg/ $\mathrm{kg}$ body weight ) on day 9, i.e. at the beginning of anagen $\mathrm{VI}$ (note the dark-blue color of the skin due to intensive melanogenesis). The first symptoms of alopecia were noticeable on day 13 p.d. (D - white arrows), and progressed through day 14 (F) up to day $15(\mathbf{H})$, while in control mice the hair follicles produced a normally pigmented hair coat (C, E, G - vehicle control, day 13, 14, 15 p.d. respectively). Note the deep-blue color of the bald skin on day 15 p.d. (H). The hair coat of the CYP-treated animals was still recovering on day $27(\mathrm{~J})$ when the skin still revealed symptoms of dystrophy (impaired pigmentation - d) beside regions of skin with hair follicles in the 2nd (recovery) anagen (r), while the hair of control mice (I) had been for a long time in deep telogen (note the pink color of the skin uncovered by shaving). 
of the splenic signal and its position prove that all the observed radical centres are isolated and each contains only one unpaired electron not coupled with any other electron or nuclear spin, therefore confirming the presence of eumelanin in the spleens (Meredith \& Sarna, 2006).

The mel- signal is distinctly weaker than both the mel+ ones, and originates from endogenous free radicals associated with mitochondrial respiration (Fig. 3; Slominski et al., 1994; Plonka et al., 2003; Elas et al., 2008). Since, due to a relatively small amount of melanin in the spleen, the melanin-derived signal is rather weak as compared to the non-melanin one, the quantitative EPR determination of melanin may be charged with a relatively substantial experimental error. Moreover, despite direct and unambiguous correlation between the presence of melanin spots on the tested spleens and the occurrence of the EPR signal characteristic of eumelanins, EPR spectroscopy does not provide resolution on the "cellular" level. The recently reported attempts to employ the technique of EPR imaging (EPRI; Godechal et al., 2012) did not provide a satisfactory resolution. As such, EPR constitutes a complementary approach to histological staining protocols which gives an insight into the distribution of melanin in the tissue.

\section{Hair cycle and melanogenesis}

In the murine trunk skin mature, melanin-producing melanocytes are present only in the anagen hair follicles (Slominski \& Paus, 1993; Slominski et al., 1994). Macroscopically it is manifested by a grey-to-black color of the skin (Fig. 4B, C), in contrast to the pink telogen skin (Fig. 4A, I), totally devoid of mature (i.e. melaninproducing) melanocytes (Fig. 5A). The changes of macroscopic skin are particularly well noticeable in the depilated skin (Fig. 4A, B). The active melanogenesis starts about day 5 p.d. (anagen III), and lasts to the end of anagen VI (day 15-16 p.d.; Müller-Röver et al., 2001). The hair follicle in anagen VI is fully developed and contains a strongly melanized hair shaft and a developed population of mature, melanin-producing melanocytes (Fig. 5B, C).

If a strong alkylating chemotherapeuticum, like CYP, is applied on day 9 p.d., i.e. at the beginning of anagen VI (Fig. 1, 4B, 5B), the hair follicles react by acute dystrophy (Braun-Falco, 1961; Kostanecki et al., 1967; Paus et al., 1994a; Slominski et al., 1996). The whole population of multiplying melanocytes and keratinocytes undergo abrupt apoptosis (Hendrix et al., 2005), resulting in alopecia (Fig. 4D, F, H), whereas in the control skin (Fig. 4C, E, G) the anagen VI hair follicles still produce normally pigmented hair shafts (Fig. 5B, C). As a result, on day 15 the CYP-treated animals are almost completely devoid of hair (Fig. 4H). The color of the skin, however, still indicates the presence of melanin. And indeed, ectopic, extracellular melanin deposition (Fig. 5D-F) is associated with both possible pathways that allow the dystrophic hair follicles to recover from the CYP-induced impairment: via dystrophic anagen (Fig. 1, 5D), or via dystrophic catagen (Fig. 1, 5E) and telogen (Fig. 1, 5F), each accompanied by a transient hair loss (Paus et al., 1994a; Slominski et al., 1996; Hendrix et al., 2005). This may be particularly well appreciated in comparison to normal anagen VI hair follicles, in the histological pictures with the FM staining of melanin (Fig. 5C). Actually, the CYP-induced dystrophy may be very strong (Hendrix et al., 2005) and it affects the apparatus of hair follicle melanogenesis, causing ectopic (hair root sheaths, sebaceous gland etc.) melanin

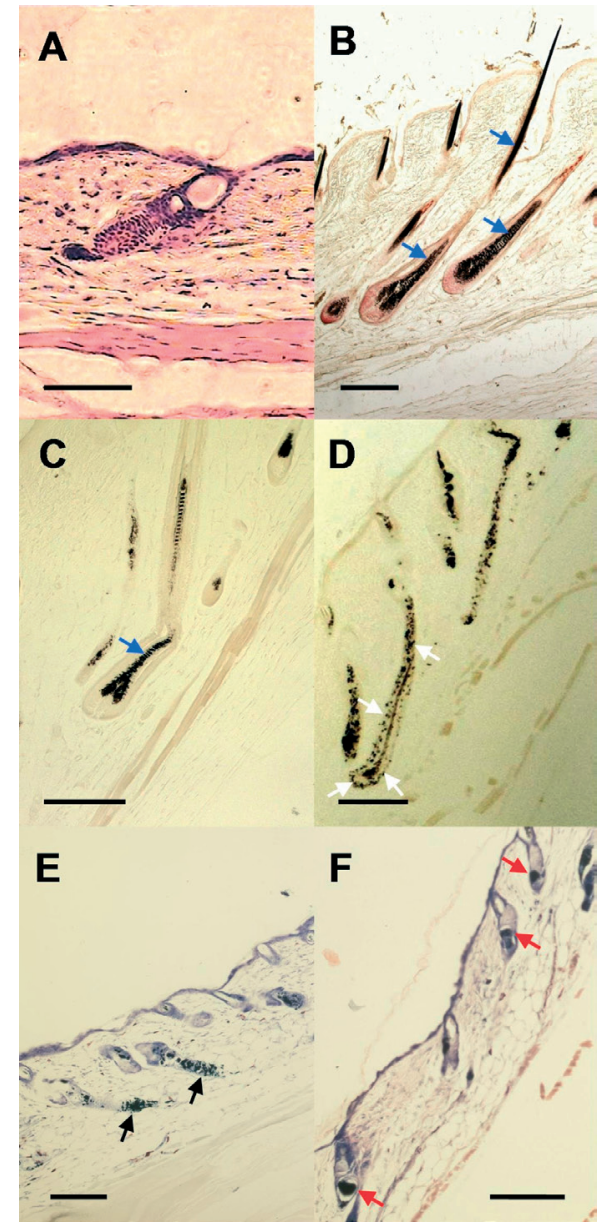

Figure 5. Histological manifestation of hair cycle-related melanogenesis and its impairment due to cyclophosphamide in C57BL/6 mice.

(A) a telogen hair follicle without melanocytes on day 0. (B, C) normal anagen $\mathrm{VI}$ hair follicles with normally pigmented hair shafts (blue arrows) on day 9 (B), and 15 p.d. (C). (D, E, F) dystrophic hair follicles on day 15 p.d in late dystrophic anagen (white arrows), late dystrophic catagen (black arrows) and dystrophic telogen (red arrows). The criteria of dystrophy - according to Hendrix et al., (2005). The black and white arrows point at both the granules of ectopic melanin, and melanin clumping in the hair channel (red arrows). This melanin was expected to be scavenged by melanophages and transported to the spleen. A, E, F - HE; B, C, D - FM. Scale bars, $100 \mu \mathrm{m}$.

deposition and clumping of the amorphous melanin mass in the hair channel (Slominski et al., 1996; Hendrix et al., 2005; Paus et al., 2013). We suspected this ectopic melanin (Fig. 5D-F) to be the source of the presumptive increase in melanin deposition expected by us to occur in the spleen after CYP-induced alopecia.

\section{Splenic melanosis during normal and CYP-impaired hair cycle}

In Fig. 6 we have shown the summary of our extensive observations of the correlation between splenic melanosis and the progress of hair cycle, at particular time points after depilation. The samples were collected over a long time and pooled from several independent experiments and from the control groups of other experiments. As the splenic melanization is a "yes-or-no" phenomenon (Plonka et al., 2005), only such an extensive study could deliver any quantitative comparisons.

And indeed, as it can be seen in Fig. 6A, the intensity of splenic melanosis changes according to the progress 


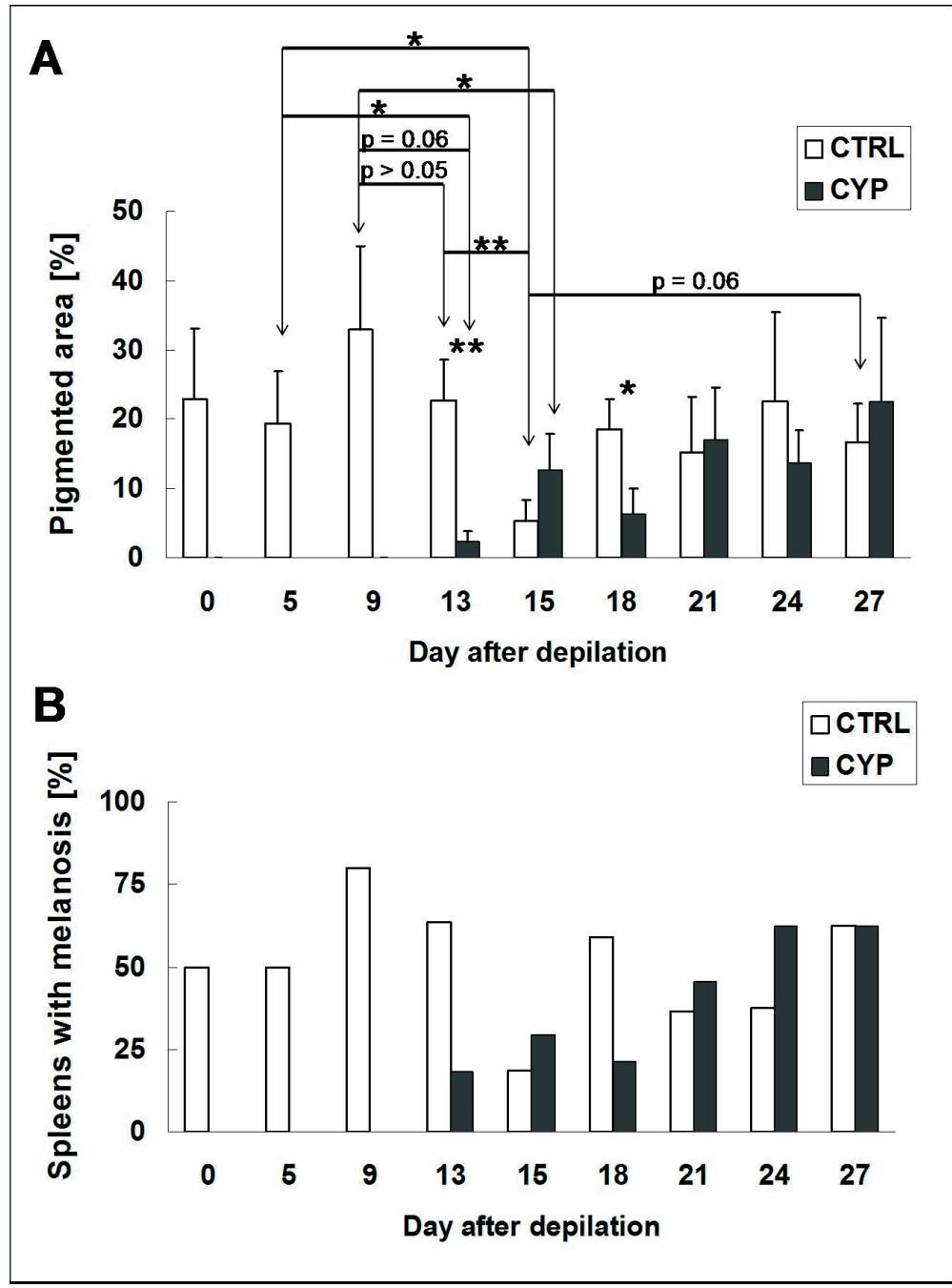

Figure 6. Splenic melanosis at particular time points of depilation induced, normal (CTRL) and dystrophic (CYP) hair cycle in C57BL/6 mice.

(A) average area of melanosis (means \pm S.E.M.); (B) total percentage of melanotic spleens observed at a particular time point. CYP, cyclophosphamide (i.p. $120 \mathrm{mg} / \mathrm{kg}$ body weight on day 9 p.d.). ${ }^{*} 0.05>p \geq 0.01,{ }^{* *} 0.01>p \geq 0.001$.

of normal hair cycling. The most important observation concerns the period shortly preceding and following the onset of catagen, with a strong drop in the melanization (Fig. 6A, B, day 15). This drop was followed by an increase during the subsequent long telogen period, confirming our earlier observations (Plonka et al., 2005). Catagen, as other stages of the synchronized hair cycle, is a phenomenon systemically influencing the murine organism (Slominski et al., 1997; Paus et al., 1999). Here we show its association with a drop in splenic melanosis in C57BL/ 6 mice.

If this is the case, the drop should be observed also in the CYP-treated animals, moreover, earlier than in the controls. And indeed, we found it happening, as shown in Fig. 6 (day 13). The decrease is abrupt and followed by a gradual re-storage of melanin in the spleens, up to the level of the control (Fig. 6, days 13-27). This can be confirmed with macroscopic (Fig. 2C, D), and histological examination of the spleens, revealing smaller and fewer deposits of melanin in the organ using the FM staining (Fig. 2P) confirmed by the MGG (Fig. 2L), and HE (Fig. $2 \mathrm{H}$ ) visualization.

As chemotherapy with CYP influences strongly the follicular melanogenesis, we expected a reverse effect in the spleens. We expected scavenging of the abundant CYP-induced ectopic melanin mass (Fig. 4D-F) by melanophages, and consequently, its massive and delayed deposition in the spleen. Meanwhile, we have found poorer melanization of CYP-treated than untreated spleens for at least 6 days (Fig. 2 D, L, H, P, 6 day 13-18) and a slow re-melanization of the spleens to the level of the control.

The overall picture of the splenic melanosis in parallel to the progress of normal or CYP-disrupted hair cycle is as follows. There are three clear phases of the phenomenon. Initially, melanosis is quite high, and culminates on day 9. Next, it drops down till day 15, i.e. the day directly preceding catagen. Finally, it increases slowly back on the border of statistical significance for the next 12 days (during telogen). If CYP is administered on day 9, the drop is much more abrupt, (the minimal value on day 13), followed by a 15-day re-pigmentation.

However, on day 18 the CYP-treated spleen pigmentation is still significantly lower than the control. The CYP-treated spleens reveal decreased pigmentation longer than the normal ones. It can be manifested both macroscopically (Fig. 2C, D), and histologically (Fig. 2G, H, $\mathrm{K}, \mathrm{L}, \mathrm{O}, \mathrm{P}$ ), as well as supported quantitatively (Fig. 6).

The peak of splenic melanization can be observed on day 9, i.e. at the onset of anagen VI. As this is also the point of the highest activity of the hair-cycleassociated melanin synthesis (Plonka et al., 1995), splenic melanosis could be associated with skin melanogenesis, if it was not for the presence of splenic melanosis in the absence of melanin synthesis in the telogen skin (from day 18 to day 27; see Fig. 4I ). During this time the CYP-treated skin is a mosaic of all the phases of normal and dystrophic hair cycle (Plonka et al., 2006; see also Fig. 4J). The lowest intensity of splenic melanization is associated with the onset of dystrophic anagen and catagen (Fig. 5D-F), which, after injection of CYP on day 9, can be observed on day 12-13, i.e. earlier than in the control animals (Paus et al., 1994a; Hendrix et al., 2005). Concluding, our observations strongly suggest that the primary factor responsible for splenic melanosis is the stage of the hair cycle, not the content of ortho- or ectopic melanin in the hair follicle. However, since even in the CYP-treated mice, ca. one fifth of the spleens (Fig. 6B) revealed weak (Fig. 6A) melanosis on day 13 we still cannot explain the reason of such a "digital" ("zero-or-one") manifestation of this phenomenon in C57BL/ 6 mice.

\section{CONCLUSIONS}

The results of our experiments lead to important practical implications. First of all, CYP abruptly and for a considerable period decreases splenic melanosis despite deposition of ectopic melanin in the CYP-treated skin. During normal catagen melanin is released from the apoptotic melano- 
cytes and keratinocytes in the form of apoptotic bodies easy to phagocyte and partially degrade (Tobin, 1998). CYP causes massive apoptosis of various cells and deposition of melanin in the form of amorphous agglomerates, which are probably difficult to be absorbed (Paus et al., 1994a; Hendrix et al., 2005). Moreover, the population of phagocytic cells (Quéméneur et al., 2003; Hirsch et al., 2004; Meinhardt et al., 2011) including splenocytes (Teryukova et al., 2011) may be transiently decreased and their capacity of devouring melanin - transiently limited. This means that the "naked", toxic melanin remains in the CYP-treated skin (see Fig. 5D-F), where it may add to the bad condition of skin and, consequently, of the whole organism (Chuong et al., 2002; Tobin, 2006). CYP may also negatively influence the spleen itself, which, besides poorer melanosis, may be manifested by e.g. a smaller size of the organ (Fig. 2C, D; Teryukova et al., 2011).

The second important conclusion concerns the systemic effects of the hair cycle: catagen, both normal and dystrophic, is always associated with a drop in the splenic melanosis. Whatever mechanism stands behind this phenomenon, catagen in the depilation-induced hair cycle causes systemic effects. Therefore, regulation of this phase is probably dependent on factors affecting the whole organism.

\section{Acknowledgements}

This study was supported in part by grant PBZKBN-101/T09/2003/12 from the Ministry of Science and Informatization, Poland, to P.M.P. The Faculty of Biochemistry, Biophysics and Biotechnology of the Jagiellonian University is a beneficiary of structural funds from the European Union (grant No: POIG.02.01.00-12064/08 - Molecular biotechnology for health).

\section{REFERENCES}

Avwioro G (2011) Histochemical uses of haematoxylin - a review. J Pharm Clin Sci 1: 24-34.

Bancroft JD, Stevens A (1982) Theory and practice of histological techniques. Churchill Livingstone, Edinburgh, Scotland.

Barcia JJ (2007) The Giemsa stain: its history and applications. Int J Surg Pathol 15: 292-196.

Barter R, Pearse AGE (1955) Mammalian enterochromaffin cells as the source of serotonin (5-hydroxytryptamine). J Pathol Bacteriol 69: 25-31.

Borovansky J, Elleder M (2003) Melanosome degradation: fact or fiction. Pigment Cell Res 16: 280-286.

Braun-Falco O (1961) Klinik und Pathomechanismus der EndoxanAlopecie als Beitrag zum Wesen cytostatischer Alopecien. Arch Klin Exp Dermatol 212: 194-216 (in German).

Chase HB (1954) Growth of the hair. Physiol Rev 34: 113-126.

Chase HB, Eaton GJ (1959) The growth of hair follicles in waves. Ann N Y Acad Sci 83: 365-368.

Chuong CM, Nickloff BJ, Elias PM, Goldsmith LA, Macher E, Maderson PA, Sundberg JP, Tagami H, Plonka PM, Thestrup-Pedersen K, Bernard BA, Schröder JM, Dotto P, Chang MHC, Williams ML, Feingold KR, King LE, Kligman AM, Rees JL, Christophers E (2002) What is the "true' function of skin? Exp Dermatol 11: 159-187.

Commoner B, Townsend J, Pake GW (1954) Free radicals in biological materials. Nature 174: 689-691.

Crichton DN, Busutil A, Price WH (1978) Splenic lipofuscinosis in mice. J Pathol 126: 113-120.

Divya L, Beyo RS, Sreejith P, Akbarsha MA,Oommen OV (2010) Skeletal muscle-melanocyte association during tadpole tail resorption in a tropical frog, Clinotarsus curtipes Jerdon (Anura, Ranoidea). Zoology 113: $175-183$.

Dry FW (1926) The coat of the mouse (Mus musculus). J Genet 16: 281340.

Elas M, Bielanska J, Pustelny K, Plonka PM, Drelicharz L, Skorka T, Tyrankiewicz U, Wozniak M, Heinze-Paluchowska S, Walski M, Wojnar L, Fortin D, Ventura-Clapier R, Chlopicki S (2008) Detection of mitochondrial dysfunction by EPR technique in mouse model of dilated cardiomyopathy. Free Radic Biol Med 45: 321-328.

Felix CC, Hyde JS, Sarna T, Sealy RC (1978) Melanin photoreactions in aerated media: electron spin resonance evidence for production of superoxide and hydrogen peroxide. I Am Chem Soc 100: 39223926.

Fontana A (1912) Verfahren zur intensiver und raschen Farbung des Treponema pallidum und anderer Spirochäten. Dermatol Wochenschr 55: 1003-1004 (in German).

Godechal Q, Leveque P, Marot L, Baurain JF, Gallez B (2012) Optimization of electron paramagnetic resonance imaging for visualization of human skin melanoma in various stages of invasion. Exp Dermatol 21: 341-346.

Hendrix S, Handjiski B, Peters EM, Paus R (2005) A guide to assessing damage response pathways of the hair follicle: lessons from cyclophosphamide-induced alopecia in mice. I Invest Dermatol 125: 42-51.

Hirsh M, Carmel J, Kaplan V, Livne E, Krausz MM (2004) Activity of lung neutrophils and matrix metalloproteinases in cyclophosphamide-treated mice with experimental sepsis. Int $J$ Exp Pathol 85: 147-157.

Kostanecki W, Kwiatkowska E, Zak R (1967) Der Einfluß des Endoxans auf die Haarmelanogenese und das Haarwachstum bei Mäusen. Arch Klin Exp Dermatol 230: 396-401 (in German).

Lazova R, Klump V, Pawelek J (2010) Autophagy in cutaneous malignant melanoma. J Cutan Pathol 37: 256-268.

Lu Z, Fischer TW, Hasse S, Sugawara K, Kamenisch Y, Krengel S, Funk W, Berneburg M, Paus R (2009) Profiling the response of human hair follicles to ultraviolet radiation. I Invest Dermatol 129: 1790-1804.

Lundqvist M, Arnberg H, Candell J, Malmgren M, Wilander E, Grimelius L, Öberg K (1990) Silver stains for identification of neuroendocrine cells. A study of the chemical background. Histochem J 22: 615-623.

Masson P (1914) La grande endocrine de l'intestin chez l'homme. Les Comptes Rendus de l'Académie des Sciences (Paris) 138: 59-61 (in French).

Mayer P (1891) Ueber das Farben mit Hämatoxylin. Mitt Zool Stat. Neapel 10: 170-186 (in German).

Mayer P (1904) Notiz über Hämateïn und Hämalaun. Z Wiss Mikrosk 20: 409-411 (in German).

McGarvey EL, Baum LD, Pinkerton RC, Rogers LM (2001) Psychological sequelae and alopecia among women with cancer. Cancer Pract 9: $283-289$.

Meinhardt C, Büning J, Fellermann K, Lehnert H, Schmidt KJ (2011) Cyclophosphamide therapy in Sweet's syndrome complicating refractory Crohn's disease - Efficacy and mechanism of action. J Crohns Colitis 5: 633-637.

Meredith P, Sarna T (2006) The physical and chemical properties of eumelanin. Pigment Cell Res 19: 572-594.

Michalczyk D, Popik M, Salwinski A, Plonka PM (2009) Extradermal melanin transfer? Lack of macroscopic spleen melanization in old C57BL/6 mice with de-synchronized hair cycle. Acta Biochim Pol 56: 343-353.

Moore S, Seemayer TA, Tremblay G (2001) The career and influence of Pierre Masson (1875-1959). Int J Surg Pathol 9: 231-236.

Müller-Röver S, Handjiski B, van der Veen C, Eichmüller S, Foitzik K, McKay IA, Stenn KS, Paus R (2001) A comprehensive guide for the accurate classification of murine hair follicles in distinct hair cycle stages. I Invest Dermatol 117: 3-15.

Paus R, Stenn KS, Link RE (1990) Telogen skin contains an inhibitor of hair growth. Br I Dermatol 122: 777-784.

Paus R, Handjiski B, Eichmüller S, Czarnetzki BM (1994a) Chemotherapy-induced alopecia in mice. Induction by cyclophosphamide, inhibition by cyclosporine $\mathrm{A}$, and modulation by dexamethasone. $\mathrm{Am} \mathrm{J}$ Pathol 144: 719-734.

Paus R, Maurer M, Slominski A, Czarnetzki BM (1994b) Mast cell involvement in murine hair growth. Dev Biol 163: 230-240.

Paus R, Christoph T, Müller-Röver S (1999a) Immunology of the hair follicle: a short journey into terra incognita. J Invest Dermatol Symp Proc 4: 226-234.

Paus R, Müller-Röver S, Van Der Veen C, Maurer M, Eichmüller S, Ling G, Hofmann U, Foitzik K, Mecklenburg L, Handjiski B (1999b) A comprehensive guide for the recognition and classification of distinct stages of hair follicle morphogenesis. I Invest Dermatol 113: 523-532.

Paus R, Haslam IS, Sharov AA, Botchkarev VA (2013) Pathobiology of chemotherapy-induced hair loss. Lancet Oncol 14: e50-e59.

Pilas B, Sarna T (1985) Quantitative determination of melanin in pigmented cells by electron spin resonance spectroscopy. In Pigment Cell 1985. Biological, Molecular and Clinical Aspects of Pigmentation. Bagnara J, Klaus S N, Paul E, Schartl M, eds, pp. 97-103. University of Tokyo Press, Tokyo.

Plonka P, Plonka B, Paus R (1995) Biophysical monitoring of melanogenesis as a tool for pigment and hair research. Arch Dermatol Res 287: 687-690.

Plonka PM, Slominski AT, Pajak S, Urbanska K (2003) Transplantable melanomas in gerbils (Meriones unguiculatus). II: Melanogenesis. Exp Dermatol 12: 356-364.

Plonka PM, Michalczyk D, Popik M, Handjiski B, Slominski A, Paus R (2005) Splenic eumelanin differs from hair eumelanin in C57BL/6 mice. Acta Biochim Pol 52: 433-441. 
Plonka PM, Handjiski B, Michalczyk D, Popik M, Paus R (2006) Oral zinc sulphate causes murine hair hypopigmentation and is a potent inhibitor of eumelanogenesis in vivo. Br J Dermatol 155: 39-49.

Quéméneur L, Michallet MC, Ferraro-Peyret C, Saint-Mézard P, Benetière J, Ducluzeau MT, Nicolas JF, Revillard JP (2003) Immunosuppressive antimetabolites inhibit induction of contact hypersensitivity while lymphoablative drugs also prevent its expression. Eur J Dermatol 13: 540-547.

Rakers S, Gebert M, Uppalapati S, Meyer W, Maderson P, Sell AF, Kruse C, Paus R (2010) 'Fish matters': the relevance of fish skin biology to investigative dermatology. Exp Dermatol 19: 313-324.

Romeis B (1991) Mikroskopische Technik. Urban \& Schwarzenberg, Muenchen, Germany (in German).

Sarna T, Plonka PM (2005) Biophysical studies of melanin: paramagnetic, ion-exchange and redox properties of melanin pigments and their photoreactivity. In Biomedical ESR. Biological Magnetic Resonance Series. Eaton SS, Eaton GR, Berliner LJ, eds, vol 23, pp 125-146. Kluwer Academic Publishers, The Netherlands, New York, Boston.

Sealy RC, Hyde JS, Felix CC, Menon IA, Prota G (1982) Eumelanins and pheomelanins: characterization by electron spin resonance spectroscopy. Science 217: 545-547.

Shirai A, Tsunoda H, Tamaoki T, Kamiya T (2001) Topical application of cyclosporine A induces rapid-remodeling of damaged anagen hair follicles produced in cyclophosphamide administered mice. J Dermatol Sci 27: 7-13.

Slominski A, Paus R (1993) Melanogenesis is coupled to murine anagen: towards new concepts for the role of melanocytes and the regulation of melanogenesis in hair growth. I Invest Dermatol 101: 90S-97S.

Slominski A, Paus R, Plonka P, Chakraborty A, Maurer M, Pruski D, Lukiewicz S (1994) Melanogenesis during the anagen-catagen-telogen transformation of the murine hair cycle. J Invest Dermatol 102: 862869.

Slominski A, Paus R, Plonka P, Handjiski B, Maurer M, Chakraborty A, Mihm MC Jr: (1996) Pharmacological disruption of hair follicle pigmentation by cyclophosphamide as a model for studying the melanocyte response to and recovery from cytotoxic drug damage in situ. J Invest Dermatol 106: 1203-1211.

Slominski A, Goodman-Snitkoff G, Maurer M, Paus R (1997) Hair cycle-associated changes in splenocyte proliferation. In Vivo 11: 101cycle-
102.
Slominski A, Tobin D J, Shibahara S, Wortsman J (2004) Melanin pigmentation in mammalian skin and its hormonal regulation. Physiol Rev 84: 1155-1228.

Slominski A, Wortsman J, Plonka PM, Schallreuter KU, Paus R, Tobin DJ (2005) Hair follicle pigmentation. J Invest Dermatol 124: 13-21.

Sundberg JP (1991) Pigmented spleens in C57BL mice. Labor Anim 25: 85-86.

Swartz HM, Mason RP, Hogg N, Kalyanaraman B, Sarna T, Plonka PM, Zareba M, Gutierrez PL, Berliner LJ (2005) Free Radicals and Medicine. In Biomedical ESR. Biological Magnetic Resonance Series. Eaton SS, Eaton GR, Berliner LJ, eds, vol 23, pp 25-74. Kluwer Academic Publishers, The Netherlands, New York, Boston.

Teryukova NP, Pogodina ON, Blinova GI, Ivanov VA (2011) Immunomodulating effect of cyclophosphamide on cytotoxic activity of rats and mice splenocytes. Cell Tissue Biol 5: 586-594.

Tobin DJ (1998) A possible role for Langerhans cells in the removal of melanin from early catagen hair follicle. Br J Dermatol 168: 795-798.

Tobin DJ (2006) Biochemistry of human skin - our brain on the outside. Chem Soc Rev 35: 52-67.

van der Heijden A, van Dik JE, Lemmens AG, Beynen AC (1995) Spleen pigmentation in young C57BL mice caused by accumulation of melanin. Labor Anim 29: 459-463.

Veninga TS, Wieringa RA, Morse H (1989) Pigmented spleens in C57BL mice. Labor Anim 23: 16-20.

Wassermann HP (1967) Extension of the concept "vertebrate epidermal melanin unit" to embrace visceral pigmentation and leucocytic melanin transport. Nature 213: 282-283.

Weissman I (1967) Genetic and histochemical studies on mouse spleen black spots. Nature 215: 315 .

Wertz J, Bolton J (1986) Electron spin resonance. Elementary theory and practical applications. Chapman \& Hall, New York, London.

Wood JM, Decker H, Hartmann H, Chavan B, Rokos H, Spencer JD, Hasse S, Thornton MJ, Shalbaf M, Paus R, Schallreuter KU (2009) Senile hair graying: $\mathrm{H}_{2} \mathrm{O}_{2}$-mediated oxidative stress affects human hair color by blunting methionine sulfoxide repair. FASEB J 23: 2065-2075.

Zawistowski S (1983) Histological technique, histology and the principles of histopathology. State Company of Medical Editors PZWL, Warsaw (in Polish). 